\title{
Synthesis and characterisation of lignin-like oligomers as a bio-inspired consolidant for waterlogged archaeological wood
}

\author{
Emily McHale $^{1,2}$, Susan Braovac ${ }^{1}$, Calin C. Steindal ${ }^{1}$, Richard B. Gillis ${ }^{3,4}$, Gary G. Adams ${ }^{3.4}$, , Stephen \\ E. Harding ${ }^{4}$, Tore Benneche ${ }^{2}$ and Hartmut Kutzke ${ }^{1}$ \\ ${ }^{1}$ Museum of Cultural History (University of Oslo, Postbox 6762 St. Olavs plass, 0130 Oslo, Norway) \\ ${ }^{2}$ Department of Chemistry (University of Oslo, Postbox 1033 Blindern, 0315 Oslo, Norway) \\ ${ }^{3}$ Faculty of Health Sciences (Queen's Medical Centre, University of Nottingham, Nottingham, NG7 \\ 2UH, United Kingdom) \\ ${ }^{4}$ National Centre for Macromolecular Hydrodynamics (University of Nottingham, Nottingham, LE12 \\ 5RD, United Kingdom) \\ Corresponding author: emily.mchale@khm.uio.no
}

\begin{abstract}
The development of new materials for the consolidation of waterlogged archaeological wood from sustainable sources is an important area of research, as the most widely used consolidant today is petroleum based. Ideally a new consolidant will interact with the existing wood structure, ensuring maximum compatibility. Lignin is often the major component remaining in archaeological wood, as it is less susceptible to degradation than holocellulose. Therefore, in order to maximise the potential for interaction with the wood cells, lignin-like oligomers have been synthesized from isoeugenol using a water soluble copper salen catalyst at $\mathrm{pH} 10$, giving a weight average $\mathrm{M}_{\mathrm{w}}$ of $1.6 \mathrm{kDa}$. Analysis by NMR spectroscopy has shown that the oligomers have a lignin-like structure with $\beta-\mathrm{O}-4^{\prime}, \beta-\beta^{\prime}$ and $\beta-5^{\prime}$ connections. A $10 \mathrm{w} / \mathrm{w} \%$ solution of the oligomers in ethyl acetate was found to thoroughly penetrate $1 \mathrm{~cm}^{3}$ samples of waterlogged archaeological wood (density of $0.146 \mathrm{~g} / \mathrm{mL}$, maximum water content of 620\%) after 14 days impregnation, as determined by FTIR spectroscopy. No impregnation material could be seen by SEM, suggesting that it coats the cell walls upon drying. This indicates that dehydrogenated polymers penetrate waterlogged archaeological wood well and have the potential to be developed into consolidants.
\end{abstract}

\section{Introduction}

Due to wide availability wood has been extensively used throughout history for a range of uses. However, wood is readily biodegraded, the degree and mechanism of decay depends very much on climate and other environmental conditions [1]. Many archaeological wooden objects are recovered from wet environments, as waterlogging limits the rapid biodegradation of all aspects of the cell wall by fungi [2]. Instead, much slower degradation by erosion bacteria, which primarily digest the holocelluloses of the cell walls, is predominant leaving the artefacts extremely fragile. As a result, they will often shrink and collapse upon drying, leading to the destruction of the object [3]. It is, therefore, essential to stabilise and conserve the artefacts prior to drying to prevent damage [4].

There are several materials currently available for consolidating waterlogged archaeological wood, but the most widely used is polyethylene glycol (PEG). PEG has been used as a consolidant for waterlogged organic archaeological material since the 1950s and was made famous by its use on the Vasa warship in Sweden [5, 6]. However, in the 60 years since its development there has been a large shift in the focus of chemistry with regards to petroleum-sourced materials [7]. With the emergence of green chemistry, there has been an increasing interest in the development of consolidants from renewable sources [8-10]. For example, sucrose has been extensively tested, but concerns with fungal and bacterial growth during and after treatment has limited its widespread application $[11,12]$. There has also been research into the use of non-reducing sugars such as lactitol and trehalose, either on their own or in combination [13]. These have shown promising results and are now used for certain 
applications, but biocides are still needed in the treatment tanks. Non-sugar-based materials are therefore of interest in order to circumvent the problem of biological attack during treatment.

Lignin is one of the most abundant biopolymers in the world and is currently a widely underutilised resource. It is a by-product of the pulp and paper industry that has very limited applications beyond being used as a fuel. There is extensive research taking place across the world into the utilisation of waste lignin and its transformation into high value products and materials [14, 15]. It was, therefore, proposed that a lignin-based material could be used as a green consolidant for waterlogged archaeological wood. Lignin is highly chemically stable and is often the most abundant remaining biopolymer in archaeological wood [16]; therefore, lignin-based materials should be compatible with the remaining wood structure. Lignin itself is too bulky to evenly penetrate archaeological wood, thus the present study focuses on lignin-like oligomers (dehydrogenated polymers, DHPs) for the consolidation of waterlogged archaeological wood.

It is known that in native lignin the $\beta-\mathrm{O}-4^{\prime}$ linkage (Fig 1) is the predominant intermolecular linker between monomer units [17]. However, this is also the linkage most readily cleaved in lignin in the presence of acid and catalytic metal ions [18]. Despite its natural abundance, in the synthesis of DHPs as lignin model compounds it has been found that the $\beta-\mathrm{O}-4^{\prime}$ linkage is only favoured at low $\mathrm{pH}$ [19]. DHPs tend to have higher ratios of the $\beta-5^{\prime}$ and $\beta-\beta^{\prime}$ linkages (Fig 1) than native lignins and at basic $\mathrm{pH}$ the $\beta-5^{\prime}$ linkage becomes the dominant linkage [20, 21]. Since the $\beta-5^{\prime}$ linkage is not as readily cleaved as the $\beta-\mathrm{O}-4^{\prime}[18]$, a high content of this linkage is desirable for DHP stability.
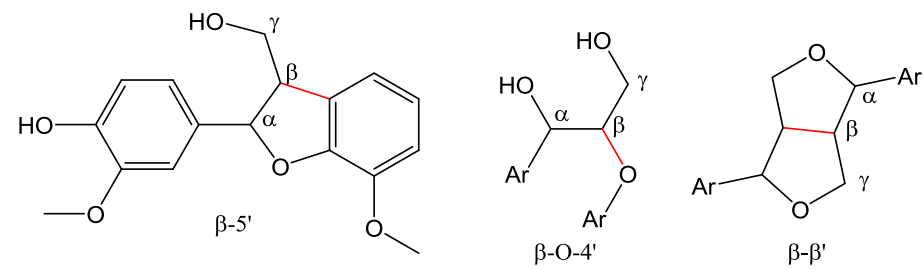

Fig 1: The structure of the major interconnecting units of lignin monomers with the bonds giving their names in red.

Another important factor to consider when synthesising a new material for consolidation is molecular weight as it has a significant effect on the penetration and consolidation abilities of materials. Compounds with molecular weights that are too high are not suitable for good penetration but compounds with low molecular weights are not likely to be strong enough to offer consolidation [22]. When treating objects with PEG molecular weights of $2000 \mathrm{Da}$ and $3000 \mathrm{Da}$ are often used to achieve a good balance of penetration and consolidation. The viscosity of the material and its solubility will also affect its ability to penetrate. The material's potential for hydrogen bonding will affect its strength; sucrose, for example, offers a higher level of consolidation than would be expected from its molecular weight alone. As a lignin-like structure would have a hydrogen bonding potential between that of PEG and sucrose it was decided to aim for a molecular weight between $1500 \mathrm{Da}$ and $2500 \mathrm{Da}$ for initial investigation.

The final factor to consider for the synthesis of DHPs for consolidation was the choice of monomer. Coniferyl alcohol is the most common monomer for the synthesis of DHPs as it is one of the natural monomers in plants [23]. However, it is very expensive to buy, whereas isoeugenol is much cheaper and structurally very similar to coniferyl alcohol, missing only one alcohol group, Fig 2. It has been shown that isoeugenol can readily polymerise to form DHPs using a transition metal catalyst [24]. Even though DHP synthesis traditionally uses enzyme based catalysts, these are less cost-effective than organometallic catalysts such as salen complexes, which have been shown to be efficient catalysts for the synthesis of DHPs with various molecular weights and properties [24]. The water-soluble copper salen catalyst $\mathbf{1}$, Fig 2 , was selected as it is well documented in the literature and can be used in a wide range of conditions. It has also been found that a higher $\mathrm{pH}$ favours higher molecular weight oligomers with the copper salen catalyst [24].

As such, this paper details the synthesis and analysis of DHPs synthesised from a relatively cheap and readily available starting material, isoeugenol, using $\mathrm{pH} 10$ with $\mathbf{1}$ as a catalyst. The DHPs have been analysed by standard methods and been investigated for their potential to penetrate waterlogged archaeological wood. 


\section{Materials and Methods}

All chemicals and reagents were purchased through Sigma Aldrich Norway except for VWR pH 10 buffer which was purchased from VWR Norway. The copper salen catalyst, 1, was synthesised according to literature methods [25]. Waterlogged archaeological wood samples, excavated in 2005 from Slagen Presterød, Vestfold County, Norway were kindly donated by the Museum of Cultural History, University of Oslo. The wood genus was identified as alder (alnus spp.). Samples used for impregnation were cut from slices with a diameter of $10 \mathrm{~cm}$ and longitudinal thickness of $1 \mathrm{~cm}$ still in waterlogged condition. Each sample had an approximate volume of $1 \mathrm{~cm}^{3}$ and rough dimensions of $2 \mathrm{x}$ $1 \times 0.5 \mathrm{~cm}$. The average density of both the core and outer regions was $0.146 \mathrm{~g} / \mathrm{mL}$ and the maximum moisture content was $620 \%$.

\section{Polymerisation of isoeugenol:}

Copper salen catalyst, 1, (359.1 mg, $0.671 \mathrm{mmol})$ was dissolved in $\mathrm{pH} 10$ buffer $(300 \mathrm{~mL})$ and hydrogen peroxide $(27.0 \mathrm{~mL}, 304.5 \mathrm{mmol}, 33 \%$ in water) was subsequently added with vigorous stirring. Isoeugenol $(4.5 \mathrm{~mL}, 30.45 \mathrm{mmol})$ was then added and the mixture was stirred for two or five days. The mixture was then diluted with saturated aqueous $\mathrm{NaCl}(300 \mathrm{~mL})$ before being extracted with ethyl acetate $(4 \times 200 \mathrm{~mL})$. The combined organic layers were dried over $\mathrm{MgSO}_{4}$ and concentrated in vacuo to give a viscous brown oil.

\section{Analytical Ultracentrifugation}

Polymerised material was assayed for molar mass using a Beckman Optima XL-I Analytical Ultracentrifuge (AUC). The sedimentation equilibrium profile was recorded using absorbance optics at a wavelength of $360 \mathrm{~nm}$, at 50k RPM $(\sim 195000 \mathrm{~g})$ at $(20.0 \pm 0.1){ }^{\circ} \mathrm{C} .12 \mathrm{~mm}$ path length double sector cells were employed with titanium centrepieces, sapphire windows and aluminium housings. Cells contained $100 \mu \mathrm{L}$ polymerised material dissolved in 100\% DMSO (non-deuterated) in the solution channels of each cell, and DMSO in the reference solvent channels. Samples were centrifuged until equilibrium achieved (approximately $24 \mathrm{~h}$ ).

Data were analysed using SEDFIT-MSTAR v1 [26]. Apparent, weight-average, molar masses $\left(\mathrm{M}_{\mathrm{w}, \mathrm{app}}\right)$ were determined by extrapolating the operational point average molar mass known as the $\mathrm{M}^{*}(\mathrm{r})$ function to the cell base [27]. Polydispersity of material was assessed by converting the original concentration vs. radius output from the AUC into $\log _{\mathrm{e}}$ (concentration) vs. relative square radius $(\xi)$, then differentiating to yield $\mathrm{M}_{\mathrm{w} \text {,app }}$ vs. $\xi$ [26]. A partial specific volume of $0.61 \mathrm{~mL} / \mathrm{g}[28,29]$ and density of DMSO $(1.1 \mathrm{~g} / \mathrm{mL})$ were used.

\section{NMR spectroscopy of DHPs}

NMR spectra were recorded on a Bruker Avance II $600 \mathrm{MHz}$ Spectrometer equipped with a TCI cryo probe and a SampleCase, using DMSO- $d_{6}$ as solvent. DHP was dissolved in DMSO- $d_{6}$ at 55-100 $\mathrm{mg} / \mathrm{mL}$ depending on sample amount and solubility. NMR spectra were acquired and processed using Topspin $3.2 \mathrm{pl6}$ and ${ }^{13} \mathrm{C}$ NMR spectra were recorded using a z-restored spin-echo pulse program to achieve a straight baseline free of hump, dip or roll [30]. An acquisition time of $0.9 \mathrm{~s}$, relaxation delay of $10 \mathrm{~s}$, a dead time of $70 \mu \mathrm{s}, 5120$ scans and a spectral width of $239 \mathrm{ppm}$ at $300 \mathrm{~K}$ was used for all acquisitions. Assignment of main lignin-like features of DHPs was performed according Ralph et al. [31].

\section{Impregnation of waterlogged archaeological wood with DHP5d}


The lignin-like oligomers were dissolved in ethyl acetate in both 5 and $10 \%$ w/w concentrations. Wood samples were then placed in the minimum amount of solution required to cover them. The treatment vessel was sealed to minimise evaporation of ethyl acetate over time. When needed the ethyl acetate was topped up to the original volume. The treatment vessels were kept at room temperature for the duration of the impregnation experiment, which was 39 days. Upon completion of treatment the wood piece was removed from solution, placed on a watch glass and air dried at room temperature for one day.

\section{FTIR spectroscopy of impregnated wood}

All FTIR measurements were performed on a Thermo Scientific iS50FT-IR Spectrometer. Slices of treated wood were taken using a micro blade razor from both the surface and core of each piece. These were then subjected to ATR-FTIR spectroscopy by placing directly onto the crystal using 32 scans at resolution $4 \mathrm{~cm}^{-1}$. Spectral range: $4000-400 \mathrm{~cm}^{-1}$.

\section{SEM of impregnated wood}

SEM images were recorded on a FEI Quanta 450 Scanning Electron Microscope. Electron images were taken using a large field detector (LFD) under low vacuum (LV) mode in order to avoid charging of the samples. The other parameters (voltage, spot size, pressure, and working distance) were modified depending on the sample with average values of $\mathrm{HV} 8.0 \mathrm{kV}$, spot size 4.5 , pressure $100 \mathrm{~Pa}$ and working distance of $8.0 \mathrm{~mm}$.

\section{Results and Discussion}

In order to investigate the ability of DHPs to consolidate waterlogged archaeological wood, it was necessary to synthesise DHPs with the required properties. It was proposed that initial testing should involve a DHP rich in $\beta 5$ linkages, low in $\beta-\mathrm{O}-4^{\prime}$ linkages and with an $\mathrm{M}_{\mathrm{w}}$ average between $1500 \mathrm{Da}$ and $2500 \mathrm{Da}$. As such a system of isoeugenol polymerised at $\mathrm{pH} 10$ with $\mathbf{1}$ was prepared using Zulauf (bulk) addition of the isoeugenol [24]. The synthesis was carried out at $\mathrm{pH} 10$ in order to favour the $\beta-5^{\prime}$ moiety over the less stable $\beta-\mathrm{O}-4^{\prime}$ and to favour a $\mathrm{M}_{\mathrm{w}}$ over $1500 \mathrm{Da}[20,21]$.

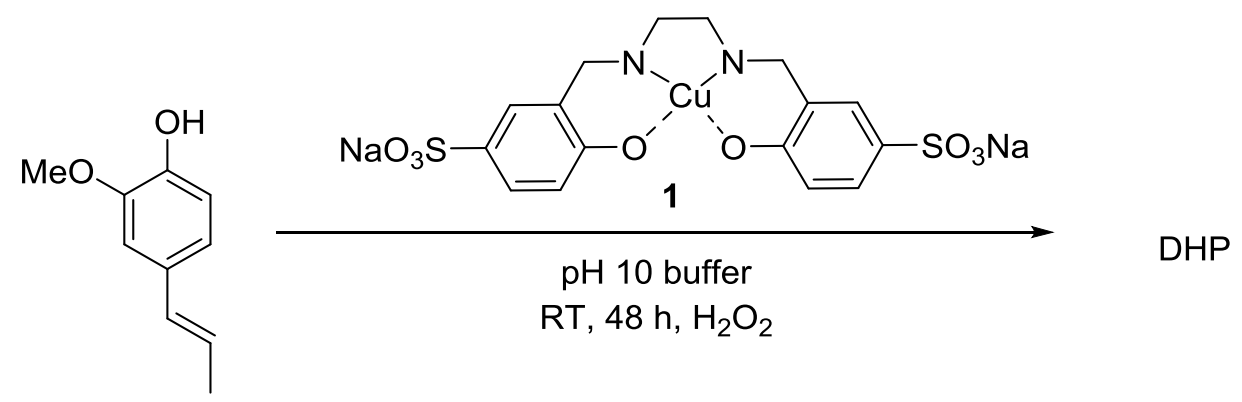

Fig 2: Reaction scheme for the synthesis of DHPs from isoeugenol using copper salen catalyst 1

Initially the polymerisation was carried out for two days, DHP2d, as described by Salantini et al. [24]. The purple colour of the copper salen in the mixture changed to pale yellow or colourless after the first day, and the catalyst was not recoverable after the polymerisation, suggesting it had been transformed and deactivated. In order to investigate whether the polymerisation occurred following the deactivation of the catalyst further polymerisations were carried out for five days, DHP5d, as well. 

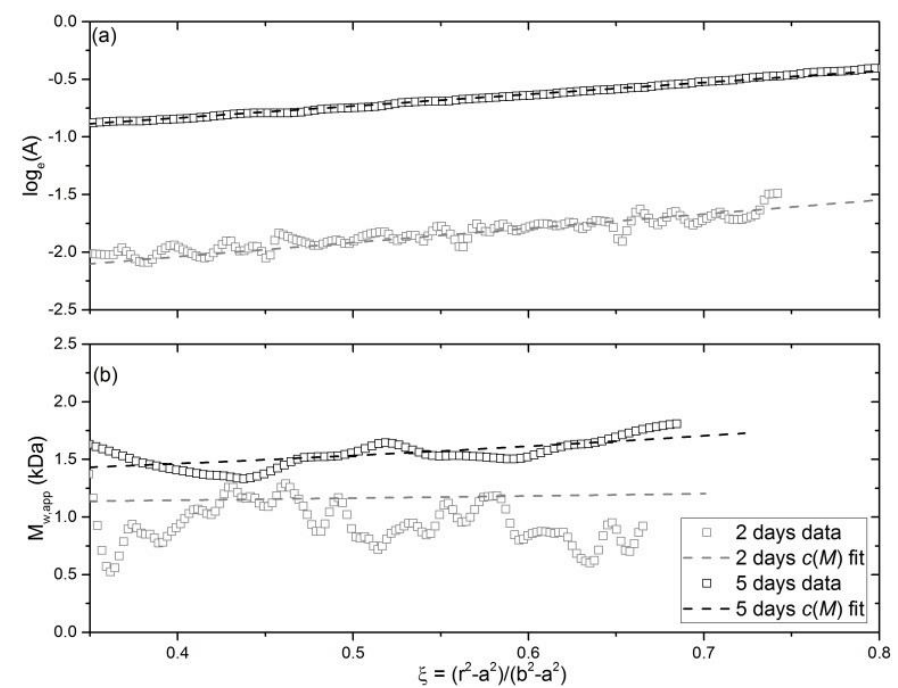

Fig 3: Results from sedimentation equilibrium AUC. Plot a) showing the logarithm of absorbance vs. the relative square radius $(\xi)$ and plot $b$ ) showing the differential of plot a) to yield point average molar mass vs. $\xi$. Lighter data points show DHP2d and darker data points show DHP5d.

\section{Molecular Weight Determination of DHPs}

Sedimentation equilibrium in the analytical ultracentrifuge showed a significant increase in molar mass for the two reaction periods. From $\mathrm{M}^{*}$ analysis using the SEDFIT-MSTAR algorithm

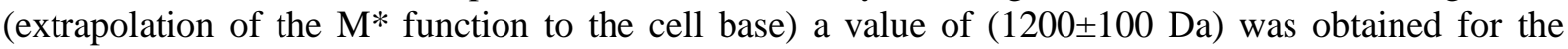
apparent weight average molar mass $\mathbf{M}_{\mathrm{w}, \text { app }}$ of DHP2d, which increased to (1600 $\left.\pm 100 \mathrm{Da}\right)$ after 5 days, DHP5d. Since these substance are very small, and the concentrations used were low $(1 \mathrm{mg} / \mathrm{mL})$ it is reasonable to take thermodynamic non-ideality effects to be effectively negligible and $\mathrm{M}_{\mathrm{w}, \mathrm{app}}=$ $\mathrm{M}_{\mathrm{w}}$, the "ideal" weight average molar mass.

These values are supported by the analysis of the point weight average molar masses $\mathbf{M}_{\mathrm{w} \text {,app }}(\mathrm{r})$ and a function of the radial displacement squared parameter $\xi=\left(\mathrm{r}^{2}-\mathrm{a}^{2}\right) /\left(\mathrm{b}^{2}-\mathrm{a}^{2}\right)$ where $\mathrm{r}$ is the radial displacement from the centre of rotation and $a, b$ the corresponding values at the air/solution meniscus and cell base respectively. $\mathrm{M}_{\mathrm{w} \text {,app }}(\mathrm{r})$ are obtained from sliding strip differentiation of plots of $\log$ concentration c(r) versus radial displacement squared, $r^{2}$, Fig 3. Despite the noise in the lower molar mass plot, a clear difference is seen. Estimates of $\mathrm{M}_{\mathrm{z} \text {,app }}$ were also made, and hence the polydispersity index $\mathrm{M}_{\mathrm{z}, \mathrm{app}} / \mathrm{M}_{\mathrm{w}, \text { app }}$ could be obtained. The longer incubation seems to show a higher degree of polydispersity, Fig 3. Nonetheless the increase in $\mathbf{M}_{\mathrm{w}}$ is encouraging.

\section{NMR spectroscopy of DHPs}

NMR spectroscopy of both the DHP2d and DHP5d confirmed that they had a lignin-like structure. In the ${ }^{13} \mathrm{C}$ spectrum of DHP5d, Fig 4, the $\beta 5^{\prime}(\alpha), \beta-O-4^{\prime}(\beta)$ and $\beta-\beta^{\prime}(\beta)$ carbon resonances can be seen in the region between 70 and $95 \mathrm{ppm}$. The presence of these peaks confirms that the DHPs have a lignin-like structure and that, as expected from the literature, all three linkages are readily formed during polymerisation at $\mathrm{pH} 10$. The ${ }^{13} \mathrm{C}$ NMR spectrum also showed a prominent peak at $191.44 \mathrm{ppm}$, suggesting that a significant proportion of the alcohol groups had been oxidised to aldehydes during the polymerisation. The exact location of the aldehyde groups within the chemical structure is unknown; however, since these groups also act as moderate hydrogen-acceptors, their presence is not expected to disrupt the potential for H-bonding with the remaining wood structure [32]. A proportion of the lignin in degraded wood is often found to be oxidised to carboxylic acid groups, which are good H-bond donors. This suggests that good compatibility between the DHPs and remaining lignin can be achieved $[33,34]$. 
The ${ }^{13} \mathrm{C}$ NMR spectrum also shows that ethyl acetate is still present within the samples [35], Fig 4, despite being oven dried at $120{ }^{\circ} \mathrm{C}$ for two days, suggesting a high affinity between the DHPs and ethyl acetate. This may be a potential concern for future conservation treatments. It is likely that ethyl acetate will continue to very slowly evaporate over several years before treated objects are completely dry. Investigation into the rate of ethyl acetate release is therefore needed to determine if this is a viable system for conservation. Slow release should not cause toxicity concerns, as it has an $\mathrm{LD}_{50}$ of $4500 \mathrm{mg} / \mathrm{m}^{3}$ over 3 hours in mice. However, it could have an effect on the object as it continues to dry, most importantly on the volume change of DHP5d upon further drying. If this is significant it could cause cracking or lack of support. As such, further investigation is required to fully determine the affect this has in situ. Alternatively, remaining ethyl acetate could be removed using a solvent exchange system. This should be investigated as the method is further developed.

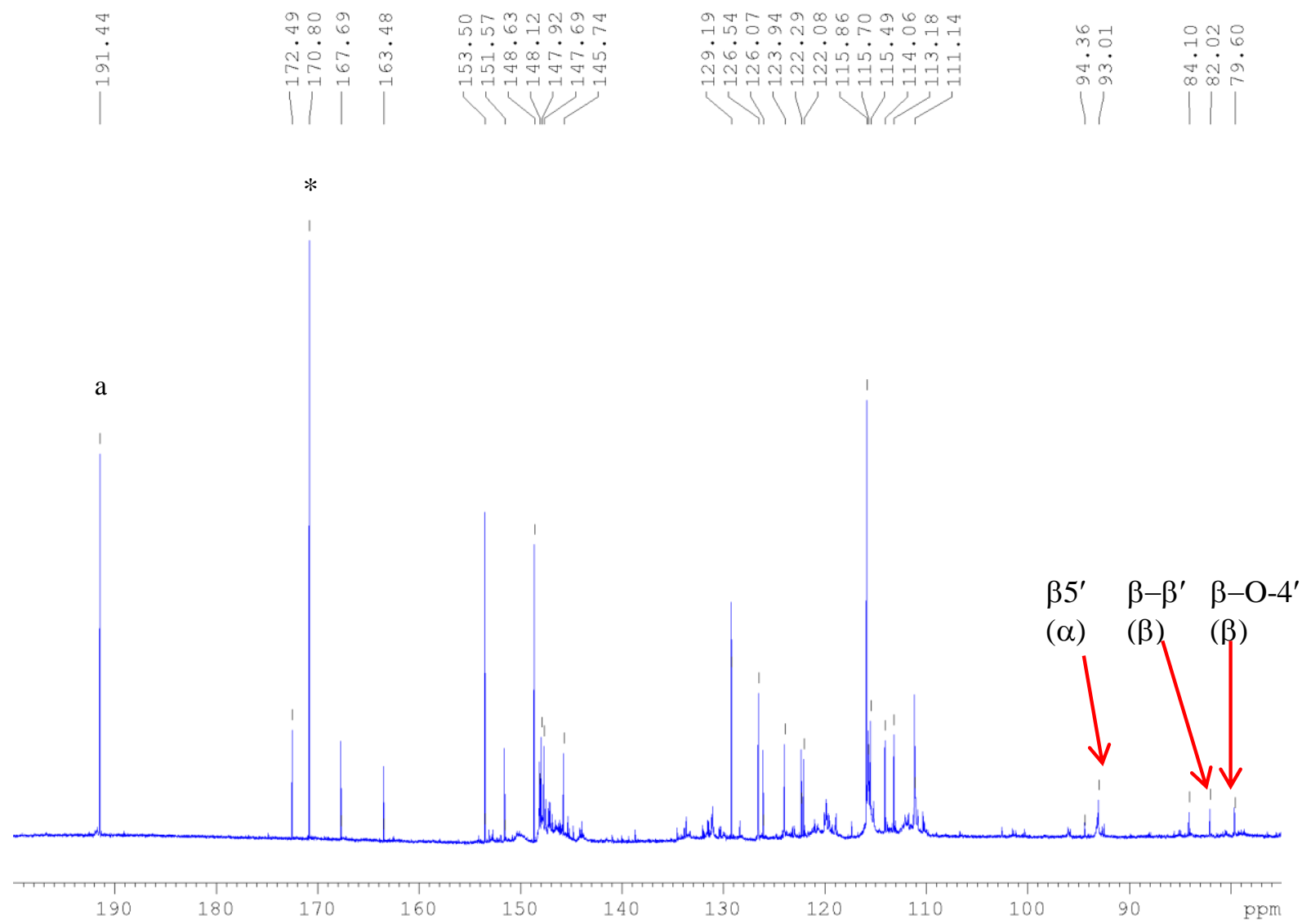

Fig 4: ${ }^{13} \mathrm{C}$ NMR spectrum of DHP5d. $\beta-5{ }^{\prime}, \beta-\beta^{\prime}$ and $\beta-O-4^{\prime}$ interconnecting units can be seen at 93.01, 82.02 and $79.60 \mathrm{ppm}$ respectively. At 191.44 ppm a strong aldehyde peak can also be observed (a). Ethyl acetate (*) can be seen at $180.80 \mathrm{ppm}$ despite drying.

\section{Impregnation studies of DHPs}

Following the synthesis and characterisation of the DHPs, it was decided that DHP5d was the most promising candidate for testing on archaeological wood. DHP5d was insoluble in water and therefore an organic solvent was needed to treat the wood pieces. Ethyl acetate was selected as it offered the best balance of low toxicity and high solubility. Samples with a volume of $1 \mathrm{~cm}^{3}$ were treated with 5 and $10 \mathrm{w} / \mathrm{w} \%$ solutions of DHP5d, as well as pure ethyl acetate for comparison.

Following treatment, ATR-FTIR spectroscopy was used to determine the presence of the DHP5d inside the wood, Fig $\mathbf{5}$. The band at $1731 \mathrm{~cm}^{-1}$ in spectrum $\mathbf{b}$ is assigned to non-conjugated carbonyl groups in lignin [36], which may correspond to the aldehyde observed in the NMR spectra. Significant overlap was observed between the infrared absorptions of the DHP5d and those of the archaeological wood, making it difficult to identify the DHPs in situ. However, the aldehyde group absorption of DHP5d was not present in the wood spectrum, and thus the emergence of a band at $1731 \mathrm{~cm}^{-1}$ in the 


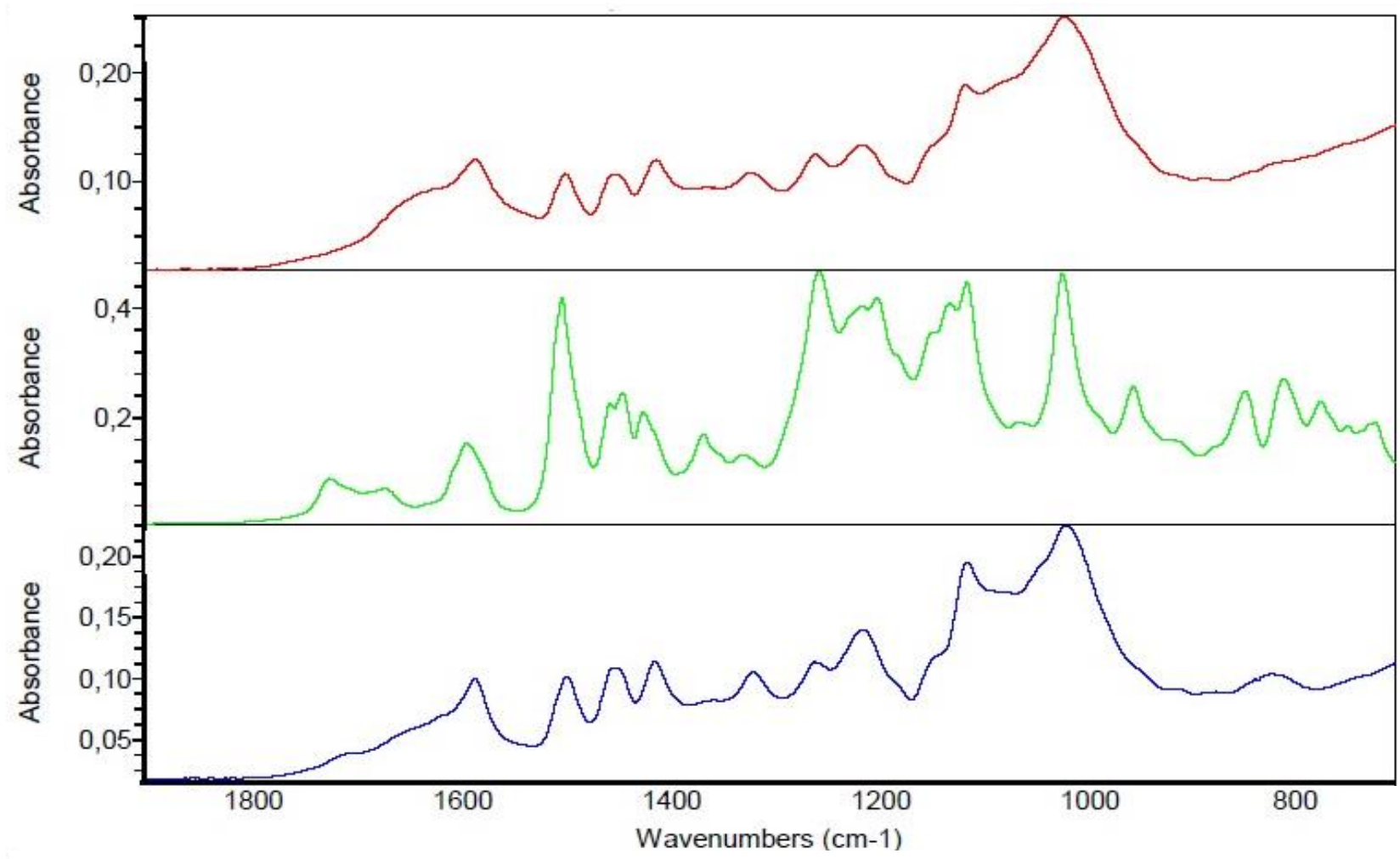

Fig 5: ATR-FTIR spectra of a) freeze dried waterlogged archaeological wood; b) DHP5d and c) air dried waterlogged archaeological wood impregnated with DHP5d. An emerging band at approximately $1731 \mathrm{~cm}^{-1}$ can be seen in c) that matches a band in DHP5d (spectrum b)

treated wood was used to indicate the presence of DHP5d in these samples. At higher concentrations the band became more prominent, confirming that it reflected the presence of DHP5d.

SEM analysis was used to compare both cross-sections and longitudinal cuts of the treated wood to untreated wood from the same object, Fig 6. It was not possible to observe DHP5d in the wood, suggesting that the material coats the cell walls in a thin layer. This is beneficial as it would enable penetration of any future treatments without the removal of the existing DHP5d consolidant.

Ethyl acetate is not a green solvent as it is produced from fossil fuels and is often unrecyclable; however, it has several advantages over water that could be beneficial in the consolidation of waterlogged archaeological wood. Firstly, it is non-corrosive to metals and therefore could be useful for composite artefacts containing both metal and wood components. Secondly, it does not readily dissolve inorganic salts, making it useful for the re-consolidation of objects that have been treated with water-soluble materials and are too fragile to withstand their removal during the re-treatment. An important example of this is some of the objects from the Oseberg collection in Norway that were previously treated with alum $\left(\mathrm{KAl}\left(\mathrm{SO}_{4}\right)_{2} \bullet 12 \mathrm{H}_{2} \mathrm{O}\right)$ and are now in an extremely fragile state [37]. In some objects, alum, which is soluble in water, is one of the main supports of degraded wood cells, so its removal may result in irreversible damage to the remaining wood structure.

In order to minimise the environmental impact of the use of ethyl acetate, its ability to be recycled following treatment has been investigated. Distillation of the DHP5d solution after treatment provided pure ethyl acetate, as ascertained by NMR spectroscopy, which could then be re-used for further treatments. Moreover, any remaining DHP5d in the solution could also be collected and recycled for use in further treatment solutions without alteration to its chemical and physical properties. The DHP5d from the impregnation solution was re-analysed following the first impregnation and again after use in a further two treatments. NMR and FTIR spectroscopy showed no alteration in the chemical structure following recycling and no alteration in average molecular weights were observed. However, further testing should be carried out to determine how many times DHPs can be recycled before alterations are observed. As a result, it is proposed that further development of this method could provide a green conservation method for the consolidation of waterlogged archaeological wood. 

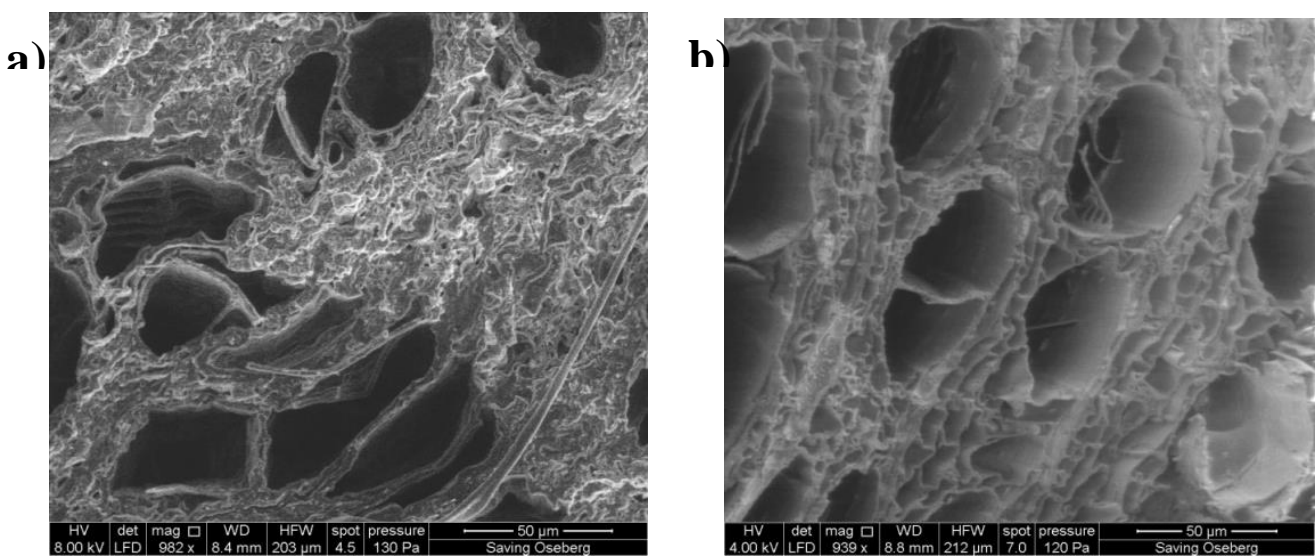

Fig 6: SEM image of waterlogged archaeological wood a) freeze dried and b) impregnated with DHP5d and air dried.

\section{Conclusion}

Oligomers synthesised via polymerisation of isoeugenol using a copper salen catalyst at $\mathrm{pH} 10$ have been found to have a lignin-like structure containing the $\beta 5^{\prime} \beta-\mathrm{O}-4^{\prime}$ and $\beta-\beta^{\prime}$ motifs as determined by NMR. Two different reaction times, two and five days, were investigated, with the five day reaction giving the highest molecular weight average of $1.6 \mathrm{kDa}$, as determined by AUC, and a relatively large amount of carbonyls present in the structure, as determined by NMR and FTIR spectroscopy. Preliminary tests on waterlogged archaeological wood using ethyl acetate solutions found that these DHPs fully penetrated $1 \mathrm{~cm}^{3}$ samples evenly and reproducibly. Although consolidation ability was not investigated at this time their reliable penetration is promising for further development as consolidants. Furthermore, both the DHPs and ethyl acetate could be recycled after wood treatment, reducing the financial and environmental impact of their use. As a result, further experiments involving evaluation of consolidation ability, penetration of larger samples and long term stability are proposed to fully assess the potential of this system as a conservation treatment for waterlogged archaeological wood.

\section{Acknowledgements}

This work was carried out under the framework of the Saving Oseberg project jointly funded by the Norwegian Ministry for Education and Research and the University of Oslo (UiO). The authors would like to thank Frode Rise at the Department of Chemistry, UiO, for his help in acquiring the NMR spectra and Guy Channell at the NCMH, University of Nottingham, for his help in acquiring the AUC data.

\section{References}

1. B. Kaye. Chemical Society Reviews 24, 35-43 (1995).

2. R. A. Blanchette. International Biodeterioration \& Biodegradation 46, 189-204 (2000).

3. $\quad$ F. M. In Archaeological Wood, pp. 3-32. American Chemical Society (1989).

4. $\quad$ D. M. Creangă. European Journal of Science and Theology 5, 57-68 (2009).

5. M. N. Mortensen, H. Egsgaard, S. Hvilsted, Y. Shashoua, J. Glastrup. Journal of Archaeological Science 34, 1211-1218 (2007).

6. E. Hocker, G. Almkvist, M. Sahlstedt. Journal of Cultural Heritage 13, S175-S182 (2012).

7. J. H. Clark. Nat Chem 1, 12-13 (2009).

8. Z. Walsh, E.-R. Janeček, M. Jones, O. A. Scherman. Studies in Conservation 0, null.

9. G. Cavallaro, G. Lazzara, S. Milioto, F. Parisi, V. Sparacino. Polymer Degradation and Stability 120, 220-225 (2015).

10. Z. Walsh, E.-R. Janeček, M. Jones, O. A. Scherman. Studies in Conservation, 1-11 (2016).

11. A. Kennedy, E. R. Pennington. Studies in Conservation 59, 194-201 (2014).

12. J. M. Parrent. Studies in Conservation 30, 63-72 (1985).

13. L. Babiński. Journal of Cultural Heritage 16, 876-882 (2015).

14. T. K. Kirk. Nat Biotech 1, 666-668 (1983). 
15. J. J. Lindberg, T. A. Kuusela, K. Levon. In Lignin, pp. 190-204. American Chemical Society (1989).

16. M. R. Roger, R. J. Barbour. Archaeological Wood. American Chemical Society (1989).

17. E. Sjöström. Wood Chemistry Fundamentals and Applications. Academic Press Inc., California (1993).

18. P. J. Deuss, K. Barta. Coordination Chemistry Reviews 306, Part 2, 510-532 (2016).

19. D. Fournand, B. Cathala, C. Lapierre. Phytochemistry 62, 139-146 (2003).

20. N. Terashima, R. H. Atalla, S. A. Ralph, L. L. Landucci, C. Lapierre, B. Monties. In Holzforschung - International Journal of the Biology, Chemistry, Physics and Technology of Wood, p. 521 (1995).

21. N. Terashima, R. H. Atalla, S. A. Ralph, L. L. Landucci, C. Lapierre, B. Monties. In Holzforschung - International Journal of the Biology, Chemistry, Physics and Technology of Wood, p. 9 (1996).

22. C. V. Horie. In Materials for Conservation, pp. 76-82. Butterworth-Heinemann (1987).

23. A. Holmgren, M. Norgren, L. Zhang, G. Henriksson. Phytochemistry 70, 147-155 (2009).

24. A. Salanti, M. Orlandi, E.-L. Tolppa, L. Zoia. International Journal of Molecular Sciences 11, 912-926 (2010).

25. A. Haikarainen, J. Sipila, P. Pietikainen, A. Pajunen, I. Mutikainen. Journal of the Chemical Society, Dalton Transactions, 991-995 (2001).

26. P. Schuck, R. B. Gillis, T. M. D. Besong, F. Almutairi, G. G. Adams, A. J. Rowe, S. E. Harding. Analyst 139, 79-92 (2014).

27. J. M. Creeth, S. E. Harding. J Biochem Biophys Methods 7, 25-34 (1982).

28. E. Alzahrani Qushmua, G. Adams Gary, B. Gillis Richard, M. D. Besong Tabot, M. S. Kök, E. Fong, A. Harding Richard, E. G. van Dam Jan, J. A. Gosselink Richard, J. Rowe Arthur, E. Harding Stephen. In Holzforschung, p. 117 (2016).

29. B. A. P. M. A. Rubio, P. Zuman. Dietary Fibres: Chemistry and Nutrition. Academic Press (1979).

30. Y. Xia, S. Moran, E. P. Nikonowicz, X. Gao. Magnetic Resonance in Chemistry 46, 432-435 (2008).

31. J. Ralph, K. Lundquist, G. Brunow, F. Lu, H. Kim, P. F. Schatz, J. M. Marita, R. D. Hatfield, S. A. Ralph, J. H. Christensen. Phytochem. Rev. 3, 29 (2004).

32. J. Schwöbel, R.-U. Ebert, R. Kühne, G. Schüürmann. Journal of Chemical Information and Modeling 49, 956-962 (2009).

33. M. P. Colombini, M. Orlandi, F. Modugno, E. L. Tolppa, M. Sardelli, L. Zoia, C. Crestini. Microchem J. 85, 164-173 (2007).

34. C. Crestini, N. M. N. El Hadidi, G. Palleschi. Microchem J. 92, 150-154 (2009).

35. G. R. Fulmer, A. J. M. Miller, N. H. Sherden, H. E. Gottlieb, A. Nudelman, B. M. Stoltz, J. E. Bercaw, K. I. Goldberg. Organometallics 29, 2176-2179 (2010).

36. O. Faix. Methods in Lignin Chemistry. Springer-Verlag Berlin Heidelberg, Germany (1992).

37. S. Braovac, H. Kutzke. Journal of Cultural Heritage 13, S203-S208 (2012). 